\title{
Diagnosing Well-Being in Work Context - Eudemonic Well-Being in the Workplace Questionnaire
}

\author{
Agnieszka Czerw ${ }^{1}$
}

Published online: 13 May 2017

(C) The Author(s) 2017. This article is an open access publication

\begin{abstract}
This article presents a proposal for a questionnaire diagnosing the well-being of employees in terms of eudemonia. This questionnaire stems from two theories on psychological and social well-being, already used in positive psychology. The construction of this questionnaire and its subsequent confirmatory studies were conducted on the group of 724 working adults. In the final questionnaire version, four factors were distinguished: positive organization; fit and development; positive relations with co-workers; and contribution to the organization. Additionally, by using the K-means cluster analysis $(N=609)$, four specific well-being profiles were distinguished: (1) moderate well-being based on relationships, (2) globally high well-being in the workplace, (3) globally low well-being in the workplace, (4) reduced well-being based on their own competences. Further analysis showed that people representing these profiles differ from each other in their level of attachment to the workplace. The guidelines regarding the actions of employers to increase the eudemonic well-being of their employees are also discussed.
\end{abstract}

Keywords Well-being · Eudemonia · Positive psychology · Work · Questionnaire

\section{Introduction}

With the rise of positive psychology the concept of psychological well-being has gained popularity among scientists and prac-

Agnieszka Czerw

agnieszka.czerw@swps.edu.pl

1 Institute of Psychology, University of Social Sciences and Humanities Faculty in Poznań, Poznań, Poland titioners. Well-being, a core term in positive psychology, is associated to quality of life, studied not only by psychologists but also by sociologists, management, education and health specialists. It seems that psychological well-being is an interdisciplinary term, since it refers to all aspects and areas of human life.

Well-being is a positive state connected to the experience of emotions and the cognitive assessment of our lives (Deci and Ryan 2008). Scientists worldwide agree that well-being can be analyzed from two standpoints (Biswas-Diener et al. 2009; Huta and Waterman 2014): hedonic - understood as pleasant life (pleasure, enjoyment, comfort), and eudemonic - valuable life (growth, authenticity, meaning). This differentiation between two types of well-being can be applied to the analysis of professional work, and more specifically to the workplace.

Until now, research on professional well-being included only the hedonic approach. The tools used so far have been limited to measuring the experience of emotions in work situations (Burke et al. 1989) and the experience of work satisfaction (e.g. Neuberger and Allerbeck 1978; Spector 1997). The eudemonic approach, connected with purpose, value and meaning, has not yet been properly discussed in the work context (Czerw 2014). The terms and tools that can be used for psychological well-being assessments should include the meaning of work (Wrzesniewski et al. 2003), engagement in work (Schaufeli and Bakker 2004), job crafting (Wrzesniewski and Dutton 2001), or a sense of meaning of work (Steger et al. 2012). So far there has only been one attempt, in Canada, to create a questionnaire directly dedicated to the research of eudemonic well-being at work (Dagenais-Desmarais and Savoie 2012). This questionnaire, written in French, has five sections: interpersonal fit at work; thriving at work; feeling competent at work; being recognized at work; and a desire for involvement at work.

Van Horn et al. (2004) attempted to create a general model of well-being at work that would include the hedonic and 
eudemonic perspectives. They tested the model in a group of teachers and the analyses confirmed the five-element mode consisting of: affective well-being (affect, commitment, lack of emotional exhaustion), professional well-being (aspiration, competence, and autonomy), social well-being (lack of students' and colleagues' depersonalization, quality of students' and colleagues' social behavior), cognitive well-being (lack of cognitive weariness), and psychosomatic well-being (lack of psychosomatic complaints). These elements constitute professional well-being in the eudemonic sense but they also include elements of social and cognitive well-being.

Apparently, the eudemonic perspective of well-being is more complicated than the hedonic. Consequently, measures referring to eudemonia at work are multidimensional and they are aimed to diagnose positive attitudes toward work and organization. Considering positive psychology's recent growth in popularity and its eudemonic perspective, it seems surprising that there are only few studies directly diagnosing eudemonic well-being in the workplace (Jayawickreme et al. 2012; Seligman 2011). The development of tools in that area seems urgent.

On the whole, the experience of well-being at work is very important as it leads to many positive consequences. Wellbeing has positive effects on employees. The most common studies conducted in that field explore the relation between eudemonic well-being and health. These studies indicate that high levels of professional well-being reduces or even prevents many health issues (e.g. hypertension, depression) that would have resulted, for instance, from stress (Hallberg et al. 2007). It is worth emphasizing that employers benefit measurably in the health of their employees. For example healthy workers lead to fewer absences in the workplace. This is not the only positive consequence for employers. Meta-analyses conducted worldwide (Ford et al. 2011) proved that high levels of professional well-being is connected with more effective use of working time, an increase in work quality, an improvement in interpersonal relations at work, less frequent and better solved conflicts at work, loyalty to the employers, civic participation, and an increase in innovation in the workplace. These are some obvious benefits, and employers should make every effort to ensure that their employees experience well-being associated with their work. Employers should be interested in workplace well-being because the experience of well-being at work is not connected to a particular profession, but in fact to the actual environment of the workplace.

\section{The Eudemonic Well-Being in the Workplace Questionnaire - Theoretical Assumptions}

In the life of almost every adult, professional work takes a significant amount of time and it can also be very engaging. It may influence the private spheres of life, through, for example work and family balance issues. Additionally, the work environment in itself constitutes a social group (Baldschun 2014). That is why, when considering professional well-being, it is quite natural to adopt an analogical perspective on personal and social well-being. We can safely assume that well-being in the professional context is something "in between" the personal well-being in a person's private life and the social well-being.

Accordingly, the creation of the well-being questionnaire for the workplace had as its starting point two eudemonic theories on well-being: Carol Ryff's model of happiness (1989) and Corey Keyes's social well-being (1998). The importance of these two theories has also been noticed by other researchers, who speculate over the issue of well-being in the professional context (Keyes et al. 2000; Page and VellaBrodrick 2009).

According to Ryff, psychological well-being consists of six elements (Ryff 1989). A combination of these elements indicates if and to what degree a particular person deals with the existentialist challenges of life (Keyes et al. 2000; Ryff and Keyes 1995). In contrast, social well-being consists of five elements, which combined, indicate if and to what extent a person functions well in social life, for example as a neighbour, co-worker or citizen (Keyes et al. 2000). As can be observed, authors of that model also include the work environment into the social environment. However, they do it only in theory. The questionnaire, which was based on that theory, does not directly relate to an organization or a group of coworkers, but to a community and the world in general (Keyes 1998).

Eudemonic Well-being in the Workplace Questionnaire (EWWQ) is based on the two models presented in Table 1.

\section{Study 1 - Eudemonic Well-Being in the Workplace Questionnaire Construction}

\section{Method}

The constructive studies were conducted in Poland via Internet. The only inclusion criterion was full-time work experience for at least one year. Data collection took two months and gathered information from 294 working adults aged between 20 and $64(M=34.31, S D=9.06)$, with general seniority between 1 and $45(M=11.29, S D=9.03)$ and seniority in organization between 1 and $38(M=6.05, S D=6.63)$. The majority were women (192 persons), workers who did not hold an executive position (221 persons), 220 persons with higher education, 74 with secondary education. Respondents represented a variety of occupations, all of which can be defined as administrative or specialized. No blue collar workers participated in this study. The subjects were Caucasian adults of Polish nationality living in large and medium-sized cities. 
Table 1 Theoretical bases of Eudemonic Well-being in the Workplace Questionnaire (EWWQ) - Model of happiness and Social well-being

Model of happiness (Ryff 1989)

-Self-acceptance - a positive attitude toward oneself

-Personal growth - a sense of constant development and fulfilment of one's potential

-Purpose in life - a feeling of purpose and having goals in the present as well as in the future

-Environmental mastery - a belief of control over the complex external environment and using the opportunities that arise, based on one's own competences

-Autonomy - an auto-determination of an individual and their independence

-Positive relations with others - having a caring, satisfying and truthful relations with others
Social well-being (Keyes 1998)

-Social integration - a sense of belonging to society

-Social acceptance - a perception of the social environment through the positive traits of its members

-Social contribution - a belief that a person is an important member of society and is able to share something valuable with it

-Social actualization - an assessment of potential and social development and a sense of purpose in that development

-Social coherence - a sense of understanding the rules of the social environment
Based on Ryff's and Keyes's theories, eleven scales of well-being in work situations were defined, and 359 items were created (around 30 items per scale). Then, eight competent judges (work and organization psychologists) assessed how these items match the definitions of scales and how they are understood. To assess how the content of items corresponds to the definitions, they used these calculations: 0 - is not included in definition; 1 - is included in the definition but is not crucial for it; 2 - is included in the definition and is crucial for it. Whereas, to assess the linguistic intelligibility: 0 - completely not understood; 1 - partially understood; 2 fully understood.

\section{Results}

After calculating the average scores for each item, 201 items were removed - those that had an average lower than 1.75 , and those that were almost equivalent in content. As the accordance of evaluators measured with W Kendall test was satisfying for that group (for matching $W(158)=.802$; $p=.001$; for understanding $W(158)=.768 ; p=.002$ ), their opinions helped to prepare 158 items of the questionnaire. The items are formed as affirmative sentences to which the subjects relate on 7-point consent scale: from 1 - I absolutely do not agree, to 7 - I absolutely agree.

Items were based on specific scales definitions, nonetheless exploratory analysis was done. This was necessary because well-being at work may be a mix of personal and social wellbeing and not just their sum. Distinguishing the dimensions of the questionnaire was done by principal component analysis with Oblimin rotation, with satisfactory $K M O=.949$ and spheric Barlett's test at $p=.001$. Eigenvalues for the distinguished factors suggested over thirteen factors (Kaiser criterion, Table 2). This is normal with over a hundred items in the questionnaire. Scree plot (Fig. 1), however, suggested between 2 and 4 factors. Basing on this, two, three and fourfactor solutions were verified. The content analysis of these solutions indicated four dimensions as the most logical.
Therefore, the four-factor solution, which explains $52.4 \%$ of variance, was accepted as final.

Next, items lowering internal consistency and reliability were removed. Items with the load factor values of less than 0.6 would be deleted first and then those, which strongly loaded three or four dimensions. The next step was to assign the proper dimensions to these items, which due to their high factor load qualified for two different dimensions. That decision was made based on initial dimension definitions. After that stage, there was an assessment of factors reliability by using the Cronbach's $\alpha$. The questionnaire was still quite long so items, whose removal would result in increased Cronbach's $\alpha$ were deleted. The final version of the questionnaire had 43 items forming four dimensions, and the percentage of the explained variance increased to $64.49 \%$ (Table 3).

Table 2 Total explained variance in the constructive research $(N=294)$. Only data for factors which increase about $1 \%$ explained variance were shown

\begin{tabular}{llll}
\hline \multirow{4}{*}{ Factor } & \multicolumn{2}{l}{ Initial eigenvalues } \\
\cline { 2 - 4 } & Total & \% of variance & \% cumulated \\
\hline 1 & 64.111 & 40.576 & 40.576 \\
2 & 8.717 & 5.517 & 46.093 \\
3 & 5.857 & 3.707 & 49.801 \\
4 & 4.131 & 2.615 & 52.415 \\
5 & 3.317 & 2.100 & 54.515 \\
6 & 2.955 & 1.871 & 56.385 \\
7 & 2.373 & 1.502 & 57.888 \\
8 & 2.130 & 1.348 & 59.236 \\
9 & 2.026 & 1.283 & 60.518 \\
10 & 1.842 & 1.166 & 61.684 \\
11 & 1.786 & 1.131 & 62.815 \\
12 & 1.558 & 0.986 & 63.801 \\
13 & 1.515 & 0.959 & 64.760 \\
14 & 1.470 & 0.931 & 65.690 \\
\hline
\end{tabular}


Fig. 1 Scree plot of factor eigenvalues (including 158 items) in the constructive research $(N=294)$. Reference line at 1.0 eigenvalue was indicated on the graph
Scree plot

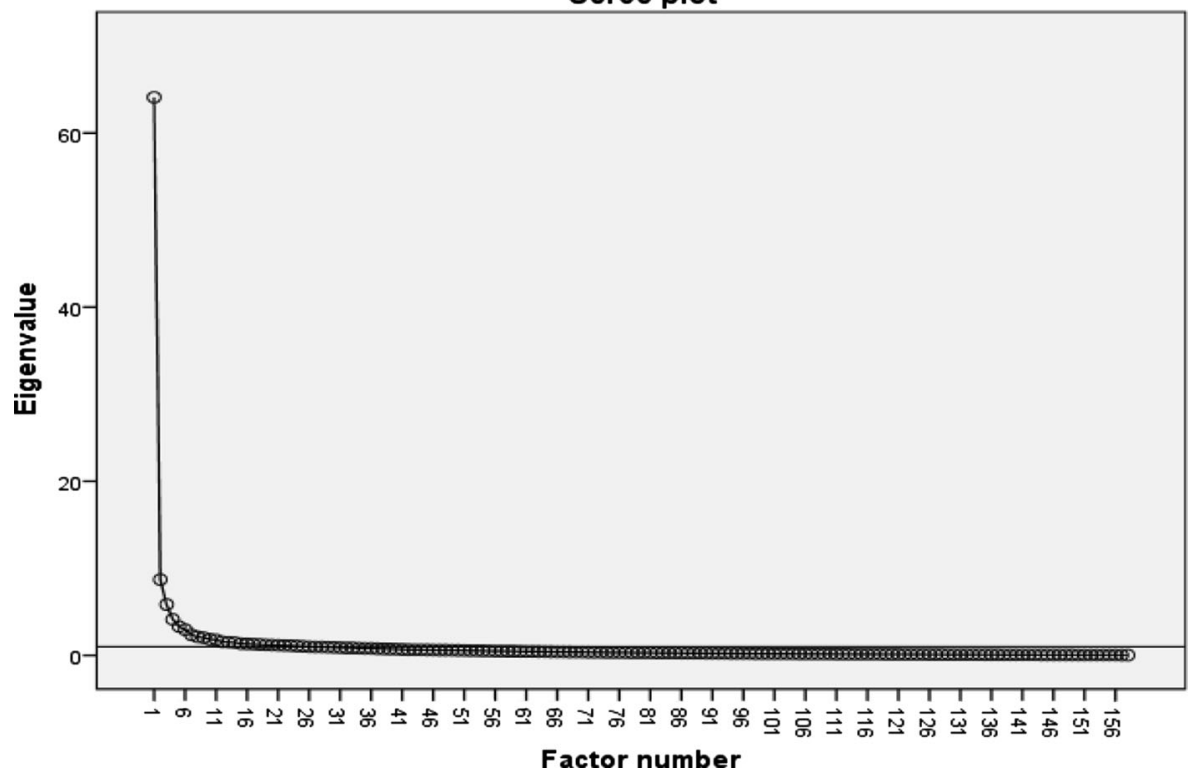

\section{Study 2 - Eudemonic Well-Being in the Workplace Questionnaire Structure Confirmation}

\section{Method}

The questionnaire in its original format has been used in several studies. As a result, another dataset was collected. This data was used to perform a confirmatory factor analysis. The sample $(N=430)$ consisted of working adults aged between 22 and $62(M=34.63, S D=8.93)$, with general seniority between 1 and $45(M=11.57, S D=8.84)$ and seniority in organization between 1 and $38(M=6.15, S D=6.48)$. The majority were women (283 persons), workers who do not hold an executive position (318 persons), 330 persons with higher and 100 with secondary education. Respondents represented a variety of occupations, all of which can be defined as administrative or specialized. The subjects were Caucasian adults of Polish nationality living in large and medium-sized cities.

The same procedure was used to extract factors, using principal component with the Oblimin rotation and with the Kaiser normalization, (four factor solution).

\section{Results}

Data analysis confirmed the structure of the questionnaire. All items of the questionnaire were divided in the same way as in the constructive factor analysis (Table 4). The factor loads for a few of them are similar in two different factors. The load in the "wrong" factor, however, is always lower. Item no. 20 is the exception: "I see my company as a community, which I am a part of." However, due to semantic matching, it was decided to leave it in the original dimension.
Factor correlation matrix for both constructive and confirmatory research were shown in Table 5.

Additionally hierarchical factor analysis was performed. Alternative EWWQ factor models were tested: 1-factor, 4factor and 4-factor hierarchical model fit analyses were conducted in LISREL 9.2 (Table 6). The 1-factor model has poor fit indices, whereas the two remaining models have similar fit. 4-factor non-hierarchical solution has slightly better characteristics (SRMR less than 0.08, RMSEA indicates an almost sufficient fit). However, CFI and NFI for both 4-factor models suggest fairly good fit (Schermelleh-Engel et al. 2003). This indicates, that the questionnaire is a good measure of general eudemonic well-being at work and a good measure of its subdimensions. Consequently, it can successfully be used to compute a general score and identify well-being profiles.

After obtaining the final form of the questionnaire (Appendix), every scale was determined including the high as well as the low scores (the negative end of the scale) for every dimension.

Positive Organization (PO): the scale associated with a sense of acceptance of the characteristics of the organization; noticing the strengths/advantages of the workplace as dominant; the feeling of general agreement on the style of functioning of the organization; the feeling that the employers and their employees are able to work for the common good; the perception of their organization as reliable and conducive to their employees; the perception of supervisors as representatives of the organizations - their positive qualities, attitudes and support to workers as evidence of the characteristics of the workplace itself.

[the negative end of the scale: the perception of their workplace as difficult to accept; a sense of disagreement on the values realized by the organization and how it functions; the lack of a sense of trust toward the organization and its 
Table 3 Total explained variance for 43 items EWWQ $(N=294)$

\begin{tabular}{|c|c|c|c|c|c|c|c|}
\hline \multirow[t]{2}{*}{ Factor } & \multicolumn{3}{|c|}{ Initial eigenvalues } & \multicolumn{3}{|c|}{$\begin{array}{l}\text { The sum of squares of loads } \\
\text { after extraction }\end{array}$} & \multirow{2}{*}{$\begin{array}{l}\text { The sum of squares of } \\
\text { loads after rotation }^{\mathrm{a}} \\
\text { Total }\end{array}$} \\
\hline & Total & $\begin{array}{l}\% \text { of } \\
\text { variance }\end{array}$ & $\%$ cumulated & Total & $\begin{array}{l}\% \text { of } \\
\text { variance }\end{array}$ & $\%$ cumulated & \\
\hline 1 & 19.953 & 46.403 & 46.403 & 19.953 & 46.403 & 46.403 & 14.935 \\
\hline 2 & 3.605 & 8.383 & 54.786 & 3.605 & 8.383 & 54.786 & 12.382 \\
\hline 3 & 2.431 & 5.652 & 60.439 & 2.431 & 5.652 & 60.439 & 10.561 \\
\hline 4 & 1.743 & 4.053 & 64.492 & 1.743 & 4.053 & 64.492 & 12.852 \\
\hline 5 & 1.018 & 2.367 & 66.858 & & & & \\
\hline 6 & .931 & 2.165 & 69.023 & & & & \\
\hline 7 & .860 & 1.999 & 71.023 & & & & \\
\hline 8 & .759 & 1.765 & 72.788 & & & & \\
\hline 9 & .742 & 1.725 & 74.513 & & & & \\
\hline 10 & .703 & 1.634 & 76.146 & & & & \\
\hline 11 & .676 & 1.572 & 77.718 & & & & \\
\hline 12 & .551 & 1.282 & 79.000 & & & & \\
\hline 13 & .540 & 1.255 & 80.255 & & & & \\
\hline 14 & .525 & 1.221 & 81.477 & & & & \\
\hline 15 & .510 & 1.187 & 82.664 & & & & \\
\hline 16 & .499 & 1.160 & 83.823 & & & & \\
\hline 17 & .466 & 1.085 & 84.908 & & & & \\
\hline 18 & .456 & 1.060 & 85.968 & & & & \\
\hline 19 & .414 & .964 & 86.932 & & & & \\
\hline 20 & .398 & .925 & 87.856 & & & & \\
\hline 21 & .371 & .862 & 88.718 & & & & \\
\hline 22 & .360 & .838 & 89.556 & & & & \\
\hline 23 & .340 & .790 & 90.346 & & & & \\
\hline 24 & .322 & .749 & 91.095 & & & & \\
\hline 25 & .314 & .730 & 91.825 & & & & \\
\hline 26 & .291 & .676 & 92.501 & & & & \\
\hline 27 & .285 & .662 & 93.163 & & & & \\
\hline 28 & .276 & .641 & 93.804 & & & & \\
\hline 29 & .263 & .611 & 94.415 & & & & \\
\hline 30 & .254 & .590 & 95.005 & & & & \\
\hline 31 & .230 & .535 & 95.540 & & & & \\
\hline 32 & .214 & .498 & 96.038 & & & & \\
\hline 33 & .198 & .461 & 96.499 & & & & \\
\hline 34 & .195 & .454 & 96.953 & & & & \\
\hline 35 & .193 & .450 & 97.403 & & & & \\
\hline 36 & .170 & .395 & 97.798 & & & & \\
\hline 37 & .167 & .389 & 98.187 & & & & \\
\hline 38 & .154 & .358 & 98.544 & & & & \\
\hline 39 & .148 & .343 & 98.888 & & & & \\
\hline 40 & .136 & .316 & 99.204 & & & & \\
\hline 41 & .129 & .301 & 99.505 & & & & \\
\hline 42 & .111 & 258 & 99.763 & & & & \\
\hline 43 & .102 & .237 & 100.000 & & & & \\
\hline
\end{tabular}

The method of factors extraction - principal component analysis

${ }^{\text {a }}$ Addition of sums squares of loads in order to obtain the overall variation is not possible when the components are correlated 
Table 4 Structural matrix of the EWWQ in constructive factor analysis $(N=294)$ and confirmatory analysis $(N=430)$; the coefficients of factor loadings above the value of 0.6 were shown; values qualifying for each dimensions were highlighted

\begin{tabular}{|c|c|c|c|c|c|c|c|c|}
\hline \multirow[b]{2}{*}{ Item No. } & \multicolumn{2}{|c|}{ Positive Organization } & \multicolumn{2}{|c|}{$\begin{array}{l}\text { Positive Relations with Co- } \\
\text { workers }\end{array}$} & \multicolumn{2}{|c|}{$\begin{array}{l}\text { Contribution to the } \\
\text { Organization }\end{array}$} & \multicolumn{2}{|c|}{ Fit and Development } \\
\hline & $\begin{array}{l}\text { Constructive } \\
\text { analysis }\end{array}$ & $\begin{array}{l}\text { Confirmatory } \\
\text { analysis }\end{array}$ & $\begin{array}{l}\text { Constructive } \\
\text { analysis }\end{array}$ & $\begin{array}{l}\text { Confirmatory } \\
\text { analysis }\end{array}$ & $\begin{array}{l}\text { Constructive } \\
\text { analysis }\end{array}$ & $\begin{array}{l}\text { Confirmatory } \\
\text { analysis }\end{array}$ & $\begin{array}{l}\text { Constructive } \\
\text { analysis }\end{array}$ & $\begin{array}{l}\text { Confirmatory } \\
\text { analysis }\end{array}$ \\
\hline 21 & 0.86 & 0.86 & 0.62 & 0.60 & & & & \\
\hline 08 & 0.85 & 0.85 & & & & & & \\
\hline 10 & 0.85 & 0.84 & & & & & & \\
\hline 26 & 0.84 & 0.81 & & & & & & \\
\hline 35 & 0.83 & 0.81 & & & & & & \\
\hline 04 & 0.78 & 0.79 & & & & & & \\
\hline 32 & 0.77 & 0.73 & & & & & & \\
\hline 12 & 0.77 & 0.80 & & & & & & \\
\hline 39 & 0.76 & 0.73 & & & & & 0.64 & 0.67 \\
\hline 30 & 0.74 & 0.75 & & & & & & \\
\hline 17 & 0.73 & 0.76 & & & & & & \\
\hline 28 & -0.69 & -0.62 & & & & & & \\
\hline 02 & 0.68 & 0.63 & & & & & 0.66 & 0.71 \\
\hline 20 & 0.66 & 0.70 & & & & & & \\
\hline 14 & & & 0.88 & 0.84 & & & & \\
\hline 27 & & & 0.84 & 0.82 & & & & \\
\hline 11 & & & 0.81 & 0.81 & & & & \\
\hline 01 & & & 0.80 & 0.77 & & & & \\
\hline 25 & & & 0.79 & 0.75 & & & & \\
\hline 18 & 0.68 & 0.72 & 0.77 & 0.72 & & & & \\
\hline 34 & & & 0.75 & 0.77 & & & & \\
\hline 42 & & & 0.71 & 0.73 & & & & \\
\hline 22 & & & 0.70 & 0.73 & & & & \\
\hline 40 & & & 0.68 & 0.68 & & & & \\
\hline 31 & & & 0.66 & 0.69 & & & & \\
\hline 09 & & & 0.65 & 0.69 & & & & \\
\hline 23 & & & & & 0.84 & 0.86 & & \\
\hline 29 & & & & & 0.79 & 0.78 & & \\
\hline 15 & & & & & 0.79 & 0.80 & & \\
\hline 03 & & & & & 0.78 & 0.76 & & \\
\hline 37 & & & & & 0.77 & 0.80 & & \\
\hline 43 & & & & & 0.76 & 0.74 & & \\
\hline 33 & & 0.62 & & & 0.74 & 0.72 & & \\
\hline 07 & & & & & 0.71 & 0.73 & 0.67 & 0.67 \\
\hline 36 & & & & & & & 0.84 & 0.84 \\
\hline 06 & & & & & & & 0.84 & 0.84 \\
\hline 24 & & & & & & & 0.83 & 0.85 \\
\hline 19 & 0.62 & 0.62 & & & & & 0.82 & 0.82 \\
\hline 38 & & & & & & & 0.77 & 0.78 \\
\hline 41 & 0.61 & & & & & & 0.77 & 0.74 \\
\hline 13 & & & & & & & 0.76 & 0.76 \\
\hline 16 & & & & & & & 0.73 & 0.75 \\
\hline 05 & & & & & & & 0.71 & 0.73 \\
\hline $\begin{array}{l}\text { Crombach's } \\
\alpha\end{array}$ & 0.91 & & 0.93 & & 0.92 & & 0.94 & \\
\hline
\end{tabular}


Table 5 Factor correlation matrix from the constructive $(N=294)$ and confirmatory $(N=430)$ research

\begin{tabular}{llllllllll}
\hline \multicolumn{2}{l}{ Factor correlations matrix } & \multicolumn{3}{c}{ constructive research } & \multicolumn{5}{c}{ Factor correlations matrix confirmatory research } \\
\hline factor & 1 & 2 & 3 & 4 & factor & 1 & 2 & 3 & 4 \\
1 & 1.000 & 0.504 & 0.505 & 0.318 & 1 & 1.000 & 0.523 & 0.392 & 0.503 \\
2 & 0.504 & 1.000 & 0.358 & 0.379 & 2 & 0.523 & 1.000 & 0.369 & 0.383 \\
3 & 0.505 & 0.358 & 1.000 & 0.269 & 3 & 0.392 & 0.369 & 1.000 & 0.505 \\
4 & 0.318 & 0.379 & 0.269 & 1.000 & 4 & 0.503 & 0.383 & 0.505 & 1.000 \\
\hline
\end{tabular}

supervisors; the perception of the disadvantages of the workplace rather than its strengths].

Fit and Development (FD): the scale measures the level of satisfaction with the performance of their professional role, and the perception of their own development; the feeling that they perform the appropriate tasks to their ability/aptitude; the feeling of being in the right place and doing their actual profession; the feeling of being in the right position for their current needs, fundamental values and beliefs, and their abilities; a feeling that the work is possible thanks to the acquisition of new or visible improvement of their own competencies that facilitate the efficient use of work.

[the negative end of the scale: a sense of mismatch to the professional role, an inadequacy of performed tasks to their abilities; a sense of not using their resources (waste), or the requirements outstripping their abilities, a desire to change work (work context and not the organization context); a sense of stagnation, lack of development, unused potential; the feeling of boredom at work and lack of interest in the performed tasks].

Positive Relations with Co-workers (PRC): the scale evaluates the perception of the quality of relationships with others in the context of work; a sense of having a good, sincere, open relationship with colleagues at the same level of hierarchy in the workplace; a sense of the possibility of trusting others at work, and of relying on other employees; the certainty that help from colleagues will be given when needed.

[the negative end of the scale: a sense of inability to establish a good, benevolent relationship with co-workers; a sense of threat from others, of hostile rivalry; a feeling of being ignored, rejected by others in the workplace].

Contribution to the Organization (CO): the scale refers to the assessment of self-worth in the context of the workplace; the belief of employees that they play a major role, as members of the organization, and have important competencies; the extent to which, the individual actions of employees value and contribute to the common good of the organization and its employees; the concept that the efficacy of the employees is responsible for the fate of the organization.

[the negative end of the scale: a feeling of lack of influence on what is happening with the organization; a sense of remoteness of their own work from the fate of the organization; a failure to see the gratitude of other employees and the workplace as a whole for the effort and the results of work of the subject].

The content of the extracted dimensions of EWWQ questionnaire allows to create a more general definition of wellbeing in the work situation. Full well-being in the organizational context means that there is a sense of mutual appreciation between the employee and his or her place of work. He/ she appreciates it because he/she accepted the values of organization, and thus the way of organizational functioning. $\mathrm{He} /$ she appreciates them also because of the positive climate created by the staff, with whom he/she shares vision of cooperation. In the end, he/she also appreciates the opportunity to realize their potential and professional development. Moreover, he/she feels well appreciated mutually, through a variety of signals flowing from the organization regarding his positive impact on the functioning of the organization. Just such a mutual appreciation between the employee and the organization is a key issue in the sense of well-being in the work situation. Therefore, the results of all four dimensions of the questionnaire can be summed calculating the overall indicator of well-being in the workplace. It is also confirmed by the hierarchical factor analysis described earlier in this text. As you can see employee wellbeing represented in this questionnaire is not a simple reflection of the two models on which originally was based. Only two dimensions directly refer to Ryff's and Keyes's models - positive relationships with coworkers (PRC) and a contribution to an organization (CO).
Table 6 Alternative factor models of EWWQ fit comparison $(N=609)$

\begin{tabular}{llllllll}
\hline Model & $S B-\chi^{2}$ & $\chi^{2} / d f$ & RMSEA & CFI & NFI & SRMR & $\Delta \chi^{2}$ \\
\hline 1 factor & $12,134.80^{*}$ & 14.11 & 0.15 & 0.91 & 0.90 & 0.097 & $7906.17^{*}$ \\
4 factors & $4228.63^{*}$ & 4.95 & 0.081 & 0.97 & 0.97 & 0.077 & \\
4 factors -hierarchical & $4344.88^{*}$ & 5.07 & 0.082 & 0.97 & 0.96 & 0.081 & $116.25^{*}$ \\
\hline
\end{tabular}

$* p<0.001 ; S B-\chi^{2}-$ Satorra-Bentler Scaled Chi-Square 
Remaining two extend beyond base models. This confirms that well-being in the organization is something slightly different from the personal and social well-being, but it has much in common with them.

\section{Study 3 - Convergent and Discriminant Validity of the EWWQ}

Verification of convergent and discriminant validity seems essential in questionnaire construction (Cronbach and Meehl 1955). Convergent validity is used to verify if and how the questionnaire dimensions correlate with external variables, chosen basing on theoretical assumptions. The discriminant validity measurement causes however some problems, so it is not often used. In this measurement, it must be demonstrated that the new questionnaire is not associated in any way with certain variables. Selecting a variable for this measurement is not easy and obvious. Of course you can choose such characteristic, which by definition is so remote that the correlation certainly will not exist. However, the demonstration of the lack of connection between so distant variables does not seem logically justified, it does not contribute to the description of the variable measured by a new questionnaire. Therefore, a good compromise seems the "multitrait-multimethod matrix" (MTMM) developed by Campbell and Fiske (Campbel and Fiske 1959) and based on repeated measurement of more than one variable.

\section{Method}

A group of eighty employees completed the questionnaire twice, with a four week gap between measures. At the second measurement, we also asked participants if there was any change in their professional situation, such as alterations in the workplace, in departments, positions, supervisors, and if there were any promotions. Only data coming from those whose situation had not changed in any of these aspects were included in the analyses. Two employees indicated a change of position. The analysis therefore takes into account the results of 78 people, 40 women and 38 men, aged from 23 to 40 years old $(M=33.92 ; S D=3.51)$. Respondents came from the same organization. They all worked in subordinate position in the administration of a company. All of them had university degrees.

\section{Results}

The correlation of the two measurements indicated a very high temporal stability. Comparisons (t-test for dependent samples) between the two measurements in all dimensions showed no significant differences (Table 7). This confirms the high stability of the measurement.

The data obtained in the temporal stability study were also used to examine convergent and discriminant validity by "multitrait-multimethod matrix" (Campbel and Fiske 1959).

In this method correlations have to fulfill four conditions. Firstly convergent validity coefficients (in the Table 8: in bold) should be above 0.9 . Secondly, these coefficients should be higher than other coefficients within the triangular area of "different traits - different methods" (in the Table 8: underlined and not in bold). This condition is fulfilled for all factors. Thirdly, convergent validity coefficients should be higher than the coefficients located in the fields of "various traits - one method" triangles (in Table 8: are not underlined and not in bold). Fourthly, correlations should be similar in all triangular. As it is shown in Table 8, this condition is also fulfilled. This proves the convergent and discriminant validity of EWQQ.

\section{Method}

The links between eudemonic well-being in the workplace and job satisfaction were also analyzed in this study. The sample consisted of 153 working adults aged between 24 and $62(M=42.50, S D=8.50)$, with general seniority between

Table 7 Correlations and differences in means between two measurements (test-retest) $(N=78)$

\begin{tabular}{|c|c|c|c|c|c|c|c|c|}
\hline \multirow[t]{2}{*}{ Pairs of variable } & \multirow{2}{*}{$\begin{array}{l}\text { Pearson's } \\
\text { correlation }\end{array}$} & \multirow[t]{2}{*}{ Mean } & \multirow[t]{2}{*}{$\mathrm{SD}$} & \multirow[t]{2}{*}{ SEM } & \multicolumn{2}{|c|}{$95 \%$ confidence interval for mean difference } & \multirow[t]{2}{*}{$\mathrm{t}(\mathrm{df}=77)$} & \multirow[t]{2}{*}{$p$} \\
\hline & & & & & Lower end & Upper end & & \\
\hline PO1 - PO2 & $.971 * *$ & .53 & 4.73 & .54 & -.54 & 1.59 & .981 & .330 \\
\hline FD1 - FD2 & $.991 * *$ & -.32 & 2.04 & .23 & -.78 & .14 & -1.386 & .170 \\
\hline PRC1 - PRC2 & $.970 * *$ & .05 & 3.75 & .42 & -.79 & .90 & .121 & .904 \\
\hline $\mathrm{CO} 1-\mathrm{CO} 2$ & $.966 * *$ & -.20 & 2.64 & .30 & -.80 & .39 & -.686 & .495 \\
\hline EWWQ1 - EWWQ2 & $.994 * *$ & .05 & 6.53 & .74 & -1.42 & 1.52 & .069 & .945 \\
\hline
\end{tabular}

$* P O$ Positive Organization, FD Fit and Development, $P R C$ Positive Relations with Co-workers, $C O$ Contribution to the Organization, $E W W Q$ Eudemonic Well-being in the Workplace Questionnaire

**Correlation is significant at the level of 0.01 (two-tailed). 
Table 8 Convergent and discriminant analysis based on intercorrelations EVOQ factors within the first measurement (test) and a second (retest) and between these measurements

\begin{tabular}{|c|c|c|c|c|c|c|c|c|c|c|}
\hline & Mean & SD & PO1 & FD1 & PRC1 & $\mathrm{CO} 1$ & $\mathrm{PO} 2$ & FD2 & PRC2 & $\mathrm{CO} 2$ \\
\hline PO1 & 56.19 & 14.793 & 1 & & & & & & & \\
\hline FD1 & 56.77 & 10.846 & $.577^{* *}$ & 1 & & & & & & \\
\hline PRC1 & 75.09 & 7.594 & $627^{* *}$ & $.627^{* *}$ & 1 & & & & & \\
\hline $\mathrm{CO} 1$ & 47.86 & 6.189 & $.269^{*}$ & $.414^{* *}$ & $.277^{*}$ & 1 & & & & \\
\hline $\mathrm{PO} 2$ & 56.10 & 13.595 & .971 & .568 & $.616^{* 7}$ & $.298^{* 2}$ & 1 & & & \\
\hline FD2 & 56.68 & 10.723 & $.571^{* *}$ & $.991^{* * *}$ & $.612^{* *}$ & $.407^{* *}$ & $.556^{* *}$ & 1 & & \\
\hline PRC2 & 74.35 & 8.287 & $.653^{* *}$ & $.627^{* *}$ & $.970^{* *}$ & $.30 Z^{* *}$ & $.652^{* *}$ & $.614^{*}$ & 1 & \\
\hline $\mathrm{CO} 2$ & 47.67 & 6.170 & $.262^{*}$ & $.394^{* *}$ & $.246^{*}$ & $.966^{* *}$ & $298^{* *}$ & $.391^{*}$ & $.277^{*}$ & 1 \\
\hline
\end{tabular}

*Correlation is significant at the level of 0.05 (two-tailed).

**Correlation is significant at the level of 0.01 (two-tailed).

2 and $43(M=20.38, S D=9.14)$ and seniority in organization between 1 and $38(M=8.73, S D=7.17)$. The majority were women (87), employees who do not hold an executive position (100 persons), 79 persons with higher and 74 with secondary education. Respondents represented a variety of occupations, all of which can be defined as administrative or specialized. The subjects were Caucasian adults of Polish nationality living in large and medium-sized cities.

Hedonic and eudemonic well-being are quite strongly positively correlated (Delle Fave et al. 2011; Fowers et al. 2010; Schueller and Seligman 2010). Although this study focuses on the eudemonic well-being, the hedonic perspective should also be included as there is a dearth of research linking the two well-being aspects in the context of work. Similar studies referring to general well-being have been conducted and they show, that the two perspectives are intertwined.

Satisfaction at work was measured using the Work Satisfaction Scale (WSC, Bajcar et al. 2011). Questionnaire diagnoses work satisfaction on the 9 characteristics of the work (colleagues, direct superiors, type of job, working conditions, career development, remuneration, working hours, employment stability, the institution as a whole), which added together give a total score.

\section{Results}

Correlation analysis showed a significant relationship between both variables in terms of the overall results $(r(152)=.74, p=.001)$ as well as all dimensions of wellbeing at work with the general index of satisfaction (Table 9).

\section{Study 4 - Well-Being Profiles in the Workplace}

Initial analyses in the previous studies showed that the structure of well-being in the working environment forms into specific distinctive patterns. In other words, participants could successfully be grouped into separate well-being profiles, based on their EWWQ results.

\section{Methods}

For this analysis, a database was created. Its data derived from another database used for confirmatory studies $(N=430)$ and two other studies conducted with EWWQ $(N=179)$ - which combined, totalled to 609 employees. The sample consists of people aged between 19 and $65(M=34.57, S D=10.16)$ with general seniority between 1 and $45(M=11.92, S D=10.04)$ and seniority in organization between 1 and $44(M=6.25$, $S D=7.25$ ). The majority were women (363 persons), workers who do not hold an executive position (418 persons), 456 persons with higher education, 153 with secondary education. Respondents represented a variety of occupations, all of which can be defined as administrative or specialized. People working on the production positions were not represented. The subjects were Caucasian adults of Polish nationality living in large and medium-sized cities.

In order to isolate the specific well-being profiles, the results were submitted to the procedure of cluster analysis using the K-means (Jain 2010; Steinley and Brusco 2011). A series of analyses was conducted for the solutions of profiles 2, 3, 4, 5 and 6 . The solution of two clusters, as it usually happens, distinguished only high and low profiles. Such a solution is

Table 9 Work satisfaction and EWWQ factors relationship $(N=153)$

\begin{tabular}{|c|c|c|c|c|}
\hline & Positive Organization & Fit and Development & Positive Relations with Co-workers & Contribution to the Organization \\
\hline Work satisfaction - total score &, $720^{* *}$ &, $642^{* *}$ & $624^{* *}$ &, $317^{* *}$ \\
\hline
\end{tabular}

**Correlation is significant at the level of 0.01 (two-tailed). 
rarely satisfactory. Only solutions starting with three clusters can give solutions of interest to the researcher. In this case, however, the analysis assuming three clusters still does not explain much. Apart from the high and low profiles, there is an additional profile composed of average results. Only a solution involving four or more clusters began to clearly differentiate the emerging results. Interestingly, variation occurred every time the profile had low results. The high profile (high scores in all dimensions) remained the same in each subsequent analysis. The average profile slightly changed, leading all the essential graphs to change, due to the separation of the low profile into several others. As a result, the number of people forming these low profiles considerably decreased each time, and the differences between the amounts in the profiles grew larger and larger. This, of course, is not intended for further analysis. Therefore, a solution had to be chosen which, on the one hand, properly differentiated the subjects, but, on the other hand, none of the profiles could apply to a very small number of people.

\section{Results}

Finally, among the few tested solutions, the 4-concentration one was chosen, which is presented in Fig. 2.

In addition, it was also verified whether the extracted profiles differ in relation to the level of the overall indicator of well-being in the environment of the workplace. It was particularly important in the case of two pairs of profiles, which had very similar results in two dimensions. The analysis of the significance of differences indicated that, despite the similarities of certain profiles, they were all significantly different from each other in terms of overall result of the questionnaire: $F(608,3)=1147.106 ; p=.001$. The differences for these pairs are: $t(281)=13.350 ; p=.001$ for profiles 1 and 4 , and $t(173)=9.495 ; p=.001$ for profiles 4 and 3 . These results in the different analyses confirmed the choice of solutions based on four profiles. ${ }^{1}$

The analysis of the results of the dimensions in each of the profiles allows them to be characterized and named appropriately. Interestingly, only one profile is on the positive side of the graph, while three are on the negative side of the graph. Admittedly, one of them oscillates around the value " 0 " but only one dimension reached a positive value.

Profile 1 - moderate well-being based on relationships the characteristic feature of this profile is that the results of the well-being dimensions are arranged on both sides of the graph, below and above the point " 0. . However, only the dimension concerning the relationships with coworkers (PRC) reaches a positive value. Other scales are

\footnotetext{
${ }^{1}$ All the more that with five profiles the differences no longer cover all the profiles.
}

still below " $0 . "$ Thus, this profile focuses on people who primarily maintain proper relationships with colleagues. The assessments of other areas are slightly reduced, but still close to the average. Employees in this profile feel that their needs and possibilities match moderately the required work tasks. This also gives them a sense of moderate growth in their professional role (FD). They do not feel that their work for their employers is appreciated and used for something important (CO). They also have the impression that their place of work is not favourable to employees, and that there is no care or systematic support for them through the use of supervisors (PO).

Profile 2-globally high well-being in the workplace - in this profile, all the dimensions are on the positive side of the graph and quite high above " 0 ." People in that profile highly assess their organization. They see it as a positive, favourable workplace to employees. They evaluate all interpersonal relationships in their company well. This applies to both relationships with supervisors, who are representatives of the organization (PO), and other employees (PRC), with whom they work. Similarly, the high rating corresponds to the sense of matching to the performed tasks and activities, and a feeling that the organization gives employees the opportunity to continuously develop their competences (FD). Employees in this profile also have a strong sense that they are valued in the workplace and that their work is significant and is used for the development of the workplace (CO).

Profile 3 - globally low well-being in the workplace - it is a profile in which all four dimensions have very low scores. It seems that the employees in this profile would rather suffer at work than derive any psychological benefits from working in their organization. They have no support from their superiors (PO) or other employees (PRC). Probably the most dominant is the sense of lack of meaning and value of their work, and even the feeling of their uselessness (CO). The same actions and tasks performed also seem illsuited to these people, to their needs and abilities and does not lead to any development of competences (FD).

Profile 4 - reduced well-being based on their own competences - it is the most varied profile, even though the majority of results lie on the "negative" side of the graph. Very lowered values apply to these dimensions, which are responsible for assessing relationships with co-workers (PRC) and support from employers and supervisors (PO). Two other dimensions reach values close to average. This means that employees feel to some extent matched to the tasks they carry out in their work (FD). They also feel that to some extent they can develop in their work (FD), and that their work is quite meaningful and to some degree important for the organization (CO). This is an image of the employees left to themselves without support from superiors and colleagues, but with 
Fig. 2 Graphical presentation of questionnaire EWWQ profiles $(N=609)$

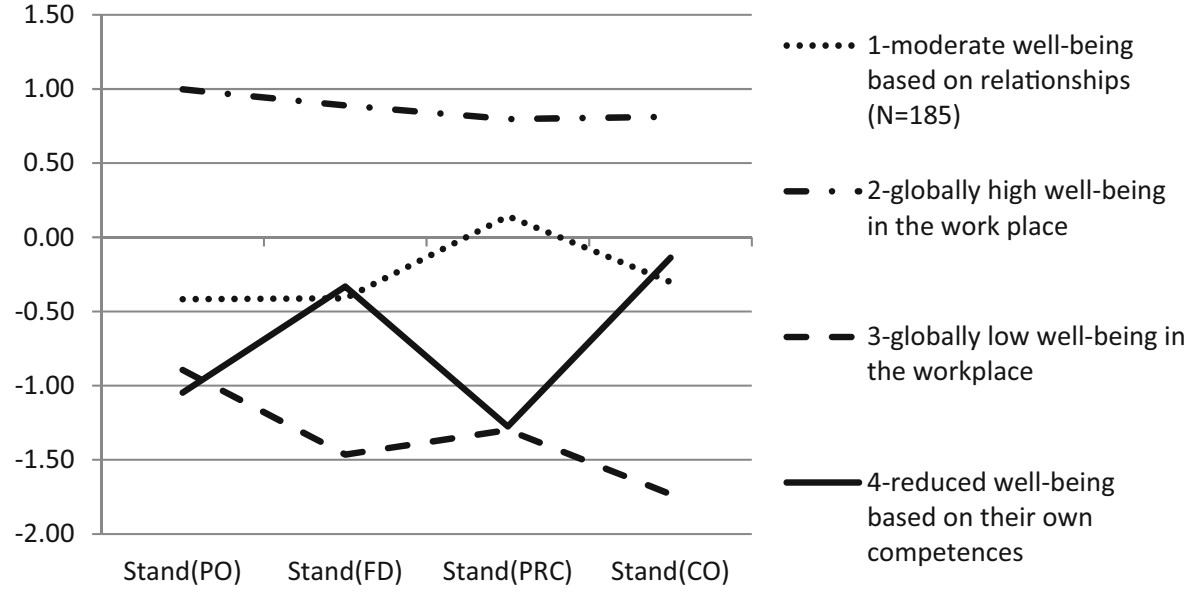

a sense that the workplace requires a lot from them (development of skills and contribution to the organization).

The next step after defining a cluster was to look at the profiles in terms of the characteristics of groups of individuals that created them. It was important to check whether the profiles differed in terms of demographic characteristics such as age, seniority, gender, education, and position.

The differences between the profiles in terms of age and seniority in the current organization were checked with variance analysis. The analysis showed (Table 10) not too large, but still significant differences in the case of age $(F(608$, $3)=2.733 ; p=.043$ ) and seniority in the organization $(F(608,3)=3.187 ; p=.023)$.

As can be seen in Table 10, profile 3 is characteristic for the lowest seniority, and profile 4 for people with the greatest seniority. In order to check whether the distribution of gender, education, and type of positions are particularly characteristic for each profile, the $\chi^{2}$ tests were used with expected values. These values are assumed to reflect the proportions of these characteristics in the entire sample.

As Table 11 shows, the considerable differences appeared only in a few cases. Profile 4 has more women than expected. Profile 1 includes more people with secondary education than anticipated, and profile 3 has more people with higher education. On the basis of all the analyses presented here concerning the characteristics of the separate clusters, it can be assumed that all profiles are reasonable and logical.

\section{Study 5 - EWQQ Profiles and Attachment to the Workplace}

The well-being of employees diagnosed in the context of the workplace should be assumed to deliver concrete benefits to the organization. Therefore, it was decided that people with a certain profile of well-being may be analyzed in terms of their loyalty to the workplace. Possibly, an indicator of that commitment was a desire to leave the organization and a willingness to make sacrifices for its benefit in difficult situations. This study can be considered also as a test of the relevance of the questionnaire. The assumption is that the higher the level of well-being at work the less the willingness to leave the organization and the greater the willingness to sacrifice for the good of the organization.

\section{Methods}

The study was conducted among 138 working adults. In the group, there were slightly more women (75) than men (63),

Table 10 Descriptive statistics for age and seniority in the organization for all well-being profiles

\begin{tabular}{|c|c|c|c|c|c|}
\hline & & Minimum & Maximum & Mean & $\mathrm{SD}$ \\
\hline \multirow[t]{2}{*}{ Profile $1(N=185)$} & Age & 22 & 62 & 33.71 & 10.08 \\
\hline & Seniority in the organization & 1 & 38 & 6.57 & 7.74 \\
\hline \multirow[t]{2}{*}{ Profile $2(N=249)$} & Age & 19 & 65 & 35.40 & 10.46 \\
\hline & Seniority in the organization & 1 & 44 & 6.14 & 6.75 \\
\hline \multirow[t]{2}{*}{ Profile $3(N=77)$} & Age & 21 & 59 & 32.35 & 9.28 \\
\hline & Seniority in the organization & 1 & 23 & 4.22 & 4.53 \\
\hline \multirow[t]{2}{*}{ Profile $4(N=98)$} & Age & 23 & 62 & 35.82 & 9.93 \\
\hline & Seniority in the organization & 1 & 33 & 7.52 & 8.84 \\
\hline
\end{tabular}


Table 11 Distributions of gender, education and position in well-being profiles

\begin{tabular}{|c|c|c|c|c|c|c|}
\hline & \multicolumn{2}{|l|}{ Expected number of persons * } & \multicolumn{2}{|c|}{ Observed number of persons } & \multicolumn{2}{|c|}{$\begin{array}{l}\text { Significances of } \\
\text { difference }\end{array}$} \\
\hline & Women $(60 \%)$ & Men $(40 \%)$ & Women & Men & $\chi^{2}(d f=1)$ & $p$ \\
\hline Profile $1(N=185)$ & 111 & 74 & 111 & 74 & 0 & 1 \\
\hline Profile $2(N=249)$ & 149 & 100 & 138 & 111 & 2.022 & 0.155 \\
\hline Profile $3(N=77)$ & 46 & 31 & 41 & 36 & 1.350 & 0.245 \\
\hline \multirow[t]{2}{*}{ Profile $4(N=98)$} & 59 & 39 & 73 & 25 & 8.348 & 0.004 \\
\hline & High school education (25\%) & $\begin{array}{l}\text { Undergraduate degree and } \\
\text { university degree }(75 \%)\end{array}$ & $\begin{array}{r}\text { High school } \\
\text { education }\end{array}$ & $\begin{array}{l}\text { Undergraduate degree } \\
\text { and university degree }\end{array}$ & $\chi^{2}(d f=1)$ & $p$ \\
\hline Profile $1(N=185)$ & 46 & 139 & 72 & 113 & 19.559 & 0.001 \\
\hline Profile $2(N=249)$ & 62 & 187 & 53 & 196 & 1.708 & 0.191 \\
\hline Profile $3(N=77)$ & 19 & 58 & 11 & 66 & 4.613 & 0.032 \\
\hline \multirow[t]{2}{*}{ Profile $4(N=98)$} & 24 & 74 & 17 & 81 & 2.965 & 0.085 \\
\hline & Managerial position (30\%) & Non-managerial position $(70 \%)$ & $\begin{array}{l}\text { Managerial } \\
\text { position }\end{array}$ & Non-managerial position & $\chi^{2}(d f=1)$ & $p$ \\
\hline Profile $1(N=185)$ & 55 & 130 & 62 & 123 & 1.268 & 0.260 \\
\hline Profile $2(N=249)$ & 75 & 174 & 84 & 165 & 1.912 & 0.167 \\
\hline Profile $3(N=77)$ & 23 & 54 & 24 & 53 & 0.076 & 0.782 \\
\hline Profile $4(N=98)$ & 29 & 69 & 21 & 77 & 3.233 & 0.072 \\
\hline
\end{tabular}

*Values rounded to whole numbers

aged between 26 and $51(M=35.4, S D=7.8)$. General seniority was between 2 and $41(M=10.12, S D=8.04)$ and seniority in organization between 2 and $38(M=6.12$, $S D=6.45$ ). The majority were employees who do not hold an executive position (98), 91 persons with higher education, 47 with secondary education. Respondents represented a variety of occupations. The subjects were Caucasian adults of Polish nationality living in large and medium-sized cities.

Apart from the EWWQ, the respondents answered two questions relating to their attachment to the workplace.

- If you had the opportunity, would you currently decide to move to another organization under the same economic conditions?

- If you knew that your organization was going through a serious crisis, would you make some sacrifices for its benefit (e.g. resignation of financial reward, agreement on free overtime, etc.)?

In both cases, the answers were given on a 5-point scale, where 1 - absolutely not, and 5 - certainly yes.

\section{Results}

Analysis of the results was performed using the variance analysis comparing with each other the four profiles of well-being. In both cases, significant differences were obtained. For the willingness to leave the organization: $F(137,3)=244.987$; $p=.001$. For the willingness to make sacrifices for the benefit of the organization: $F(137,3)=185.755 ; p=.001$. The comparison of averages between the profiles is shown in Figs. 3 and 4.

As these graphs show, people from both profiles with poor well-being ("globally low well-being in the workplace" and "reduced well-being based on their own competences") think very similarly (the difference being not statistically significant). They have a high willingness to change jobs and are unwilling to make sacrifices for the organization. The representatives of the profile "global well-being in the workplace" do not want to leave their organization and are willing to make sacrifices for it. However, among the representatives of the profile "moderate well-being based on relationships," there is a noted lack of readiness to leave, but also a lack of readiness to make sacrifices. Most of the results are not surprising. People with low well-being profiles have results showing a low or even a lack of attachment to their workplace. Those with high levels of well-being are highly attached to the organization. The most interesting result was undoubtedly found among those with a moderate level of well-being. Taking into account the shape of the profile and the fact that the only high score in this profile refers to relationships with colleagues, it turns out that this dimension of well-being is likely to play a key role in the level of readiness to leave the organization. Possibly, good relationship with others discourage employees from taking the decision to leave. In contrast, good interpersonal relations are not enough to warrant dedication to the workplace. It seems that we are dealing with a mental separation of people/employees from the workplace as such. It becomes evident that, despite the desire to maintain relationships with co-workers, some employees do not understand that 
Fig. 3 Mean differences between well-being profiles for willingness to leave the organization

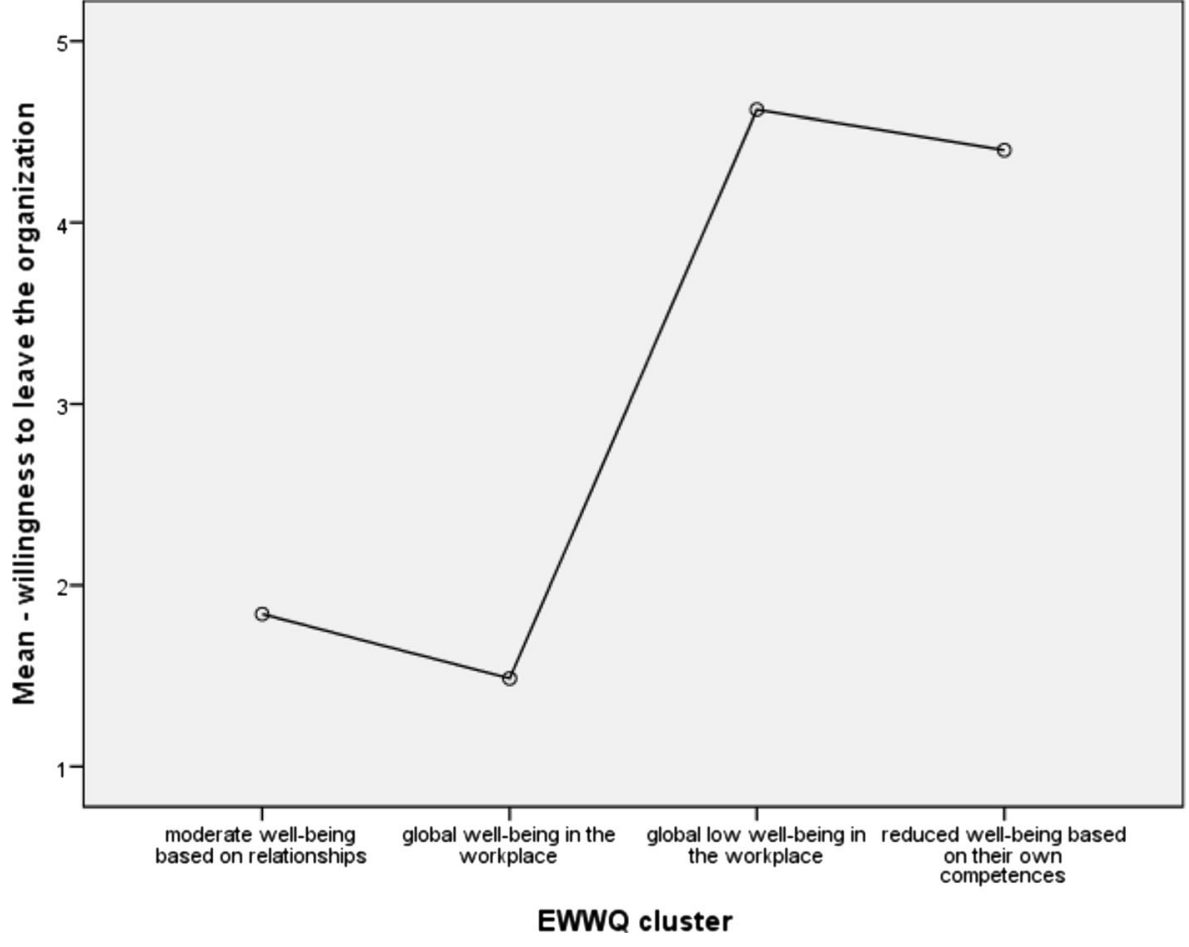

An interesting observation can be drawn from this study that could be useful to HR management in the workplace. If employers depend on the commitment of their employees, in the context of their so-called continuance commitment (a term derived from Meyer and Allen's approach Meyer and Allen 1991), then perhaps the most important is to nourish proper interpersonal relationships. This, however, is not enough

Fig. 4 Mean differences between well-being profiles in the willingness to make sacrifices for the organization

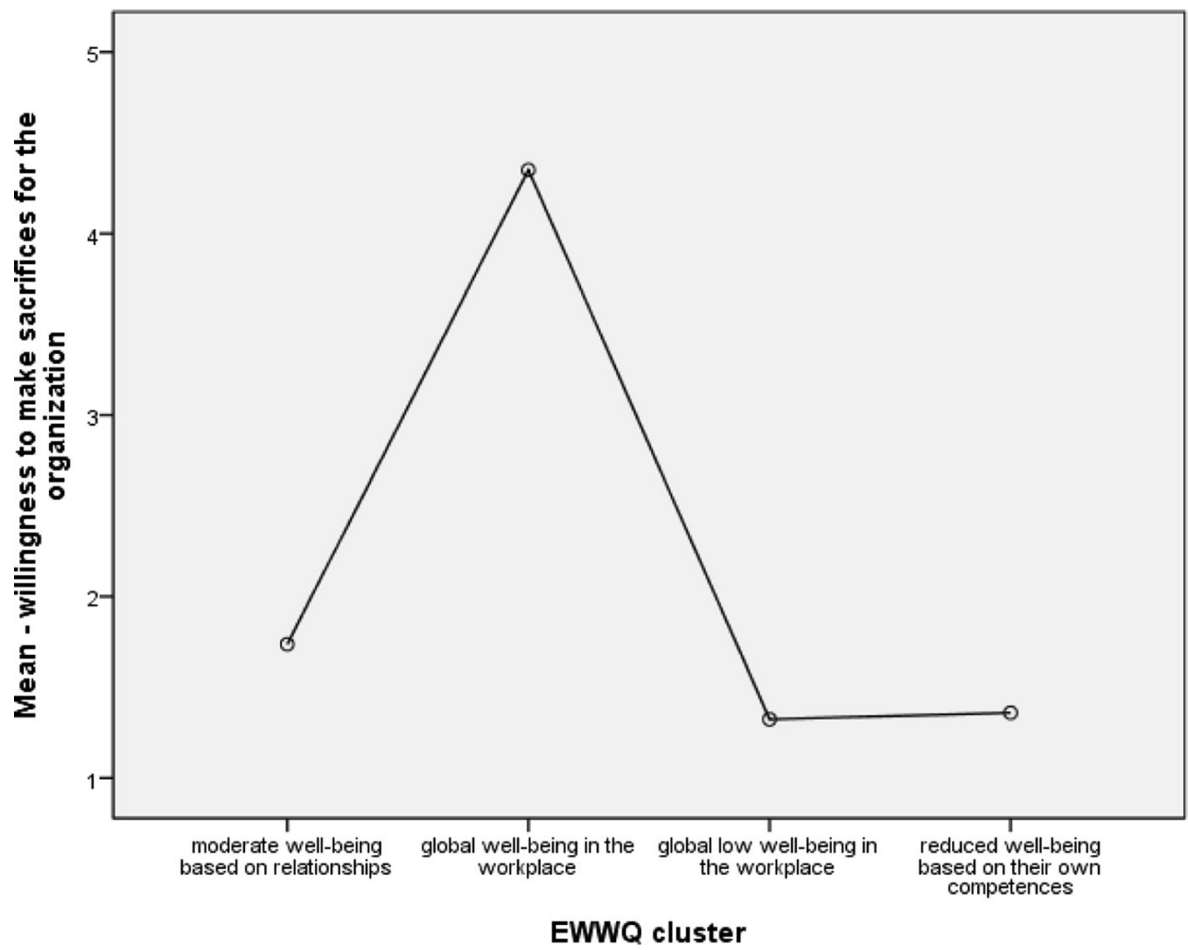


when the purpose of HR is a full commitment of employee to the organization and the possibility of reliance on their employees regardless of good or bad organization condition. In this case, the aim must be to ensure that all components of well-being in the workplace are at the highest level.

\section{Discussion}

It seems that the results of this study can be linked to various psychological concepts from within the area of work wellbeing, and in particular to eudemonic well-being at work.

The work can be seen by the employee as valuable when he can realize values important for him. It could be related with tripartite model of peoples orientations to the work as a job, career or calling (Wrzesniewski 2003). In each of these work orientations an employee will be looking for some important values for him in work situation. Additionally, treating work as something very important in person's life appears most clearly in the context of work ethic concept (Miller et al. 2002). Another aspect of eudemonic well-being at work is the realization of values important for employees in the context of work. That issue was singled out in the 70s of the twentieth century. In a short time, a number of work values theories and methods to measure them were described. For example Super's, Furnham's or Warr's theories should be mentioned in that context (Furnham 2008). All these approaches, however, concern the issue of the job itself and not the organization context. A reference to the well-being in organization can be found in person-organization fit theory (Kristof 1996; Kristof-Brown and Billsberry 2012). Especially supplementary fit highlighting the similarity between the organization and the employee (in the context of realized values) is associated with the concept of well-being in the workplace. Another variable, which can be considered similar to the concept of well-being in the workplace is an organizational commitment (Meyer and Allen 1991). One of the three components that make up this construct is affective commitment. It is most similar to the well-being in the workplace. The affective component is the emotional attachment to the organization or employee commitment and identification with it. Employees with a strong affective attachment continue to remain in the organization because they want to (not have to). They accept it and they like it. All these variables although similar to eudemonic well-being in the workplace are not identical with it. A sense of meaning to their work seems to be the nearest concept (Steger et al. 2012), but this is still the prospect of work but no a prospect of workplace. Therefore, it seems that the proposed questionnaire in this article provides a unique proposal for measuring eudemonic well-being in the workplace.

The new questionnaire described in the article has good psychometric characteristics. Whereas the profiles of well- being seem to differentiate employees with different attitudes towards their work.

Eudemonic professional well-being is important for at least two reasons. For the employee, it may lead to numerous personal benefits. For the organization, it may lead to more productive employees and less employee turnover. Therefore, organizations may need to be encouraged to pay more attention to their employees' well-being.

If the prospect of eudemonic well-being concerns the meaning of work, so in quite a natural way, it should also be associated with placing goals. However, the objectives placed for employees by supervisors should take into account several principles (Sirgy 2006). Firstly, eudemonic well-being of workers can be increased by providing them with goals of personal importance to them, connected with the implementation of important values or giving them a sense of selfdevelopment (cf. the concept of person-organization fit in terms of values, Cable and Edwards 2004). It is, therefore, a subjective value of the goal. Secondly, goals should be ambitious - not too easy, but possible to realize with an increased effort from employees. This level of ambition also demands an engagement from employees, or even flow (Csikszentmihalyi 2009). The well-being of employees will also increase when they are allowed to pursue objectives that are useful to the organization. These are the kinds of employees the workplace can use to its own advantage. This will also provide them with a precise sense of the meaning of their work (cf. dimension of "contribution to the organization" in the EWWQ questionnaire). And finally, the organization (supervisor) should ensure that the employee experienced that the goal was actually achieved (cf., the sense of achievements in PERMA model, Seligman 2011). This can be accomplished, for example, through feedback once the goal has been accomplished.

It appears that well-being in the environment of the workplace in terms of eudemonia, seen from the perspective of the management of the organization, may be more important than in the hedonic approach. Note, however, that both types of well-being, according to studies (Steger and Dik 2009), are likely to be strongly inter-related.

Naturally, there are some limitations to this study. First, the sample was not balanced in terms of some demographic characteristics. There was an overrepresentation of women, persons with high education and white-collar employees. Future research should supplement this sample with people with primary education, production workers and men. Moreover, it would be worthwhile to check the relationships between EWQQ and other well-being dimensions referring to work (e.g. work engagement) and other dimensions referring to general well-being (e.g. hedonic, such as emotions at work). It seems that a study of employees' actual behaviors towards their organizations might also yield interesting results. 


\section{Compliance with Ethical Standards}

Conflict of Interest Author declares that she has no conflict of interest.

Ethical Approval All procedures performed in studies involving human participants were in accordance with the ethical standards of the institutional and/or national research committee and with the 1964 Helsinki declaration and its later amendments or comparable ethical standards. Participation in the survey was on the voluntary basis and anonymous.

\section{Appendix}

\section{English version of questionnaire}

All employees in some way evaluate their work (tasks) and the place where they work. This questionnaire is a personal assessment.

Please think about the workplace, which you currently are working in and try to assess how well each of the following statements describes your views and feelings about working in this organization.

Please note that the answers should reflect only your personal feelings about the work, and not as it should be, or what other workers probably think. Please avoid the answer "hard to say."

The words "organization" or "company" are to be understood as a company in which you are currently working.

1. I have a good relationship with co-workers

2. Thanks to my work I can fulfil my personal goals and realize the values important to me

3. Thanks to my work, my company has achieved measurable benefits

4. The organization that I work for has more pros than cons

5. I feel that the work I do is important

6. I think that the work I am doing is interesting

7. I think that what I do for the organization is important

8. I agree with the operating manner of the company I work for

9. In case of problems at work, I can count on the support of the people with whom I work

10. The transparency of rules in my company is really making my work easier

11. I feel that with the other employees of my organization we create a coherent team

12. I have a feeling that in my company every employee is important

13. Through my work I learned many valuable things

14. I get along well with co-workers

15. I feel that through my work the organization can pursue their goals

16. I believe that the position on which I work is adequate to my skills
17. I belief that I have real influence on the decision making process in my company

18. The atmosphere at my work is welcoming and friendly

19. My job allows me to develop

20. I see my company as a community, which I am a part of

21. My company is a positive workplace

22. I think that my colleagues and I are guided by similar values

23. I believe that my work contributes to the development of my company

24. My job suits me

25. I believe I am liked and accepted at work

26. Thanks to the good organization of the work load in my company, my work makes sense

27. I can rely on co-workers

28. In fact, I do not know what rules my organization is governed by

29. I know that my work is an important element in the operation of my company

30. My supervisors appreciate my work

31. In my work, I generally meet people similar to me, with whom I get along well

32. My supervisor is ready to help me if I need it

33. I am an important part of my organization

34. I trust my co-workers

35. I am proud of my company

36. I think I picked a good career path

37. I feel that my work gives much to the company I work for

38. I have the ability to continuously improve my competence

39. I am strongly connected with the organization that I work for

40. I feel that others want to work with me

41. I can see the sense in the tasks I perform

42. Me and my colleagues have similar goals

43. I believe that my company needs my competence to operate

Open Access This article is distributed under the terms of the Creative Commons Attribution 4.0 International License (http:// creativecommons.org/licenses/by/4.0/), which permits unrestricted use, distribution, and reproduction in any medium, provided you give appropriate credit to the original author(s) and the source, provide a link to the Creative Commons license, and indicate if changes were made.

\section{References}

Bajcar, B., Borkowska, A., Czerw, A., \& Gąsiorowska, A. (2011). Satysfakcja z pracy w zawodach z misja społeczna: psychologiczne uwarunkowania (Job satisfaction in occupations with a social mission: psychological couses). Gdańsk: Gdańskie Wydawnictwo Psychologiczne. 
Baldschun, A. (2014). The six dimensions of child welfare employees' occupational well-being. Nordic Journal of Working Life Studies, 4(4), 69-87.

Biswas-Diener, R., Kashdan, T., \& King, L. (2009). Two traditions of happiness research, not two distinct types of happiness. The Journal of Positive Psychology, 4(3), 208-211.

Burke, M. J., Brief, A. P., George, J. M., Roberson, L., \& Webster, J. (1989). Measuring affect at work: Confirmatory analyses of competing mood structures with conceptual linkage to cortical regulatory systems. Journal of Personality \& Social Psychology, 57(6), 1091-1102.

Cable, D. M., \& Edwards, J. R. (2004). Complementary and supplementary fit: A theoretical and empirical integration. Journal of Applied Psychology, 89(5), 822-834. doi:10.1037/0021-9010.89.5.822.

Campbel, D. T., \& Fiske, D. W. (1959). Convergent and discriminant validation by the multitrait-multimethod matrix. Psychological Bulletin, 56, 81-105.

Cronbach, L. J., \& Meehl, P. E. (1955). Construct validity in psychological tests. Psychological Bulletin, 52(4), 281-302. doi:10.1037/ h0040957.

Csikszentmihalyi, M. (2009). Flow. In S. J. Lopez (Ed.), The encyclopedia of positive psychology (pp. 394-400). Chichester: WileyBlackwell.

Czerw, A. (2014). Well-being at work - The essence, causes and consequences of the phenomenon. International Journal of Contemporary Management, 13(2), 97-110.

Dagenais-Desmarais, V., \& Savoie, A. (2012). What is psychological well-being, really? A grassroots approach from the organizational sciences. Journal of Happiness Studies, 13(4), 659-684. doi:10. 1007/s10902-011-9285-3.

Deci, E. L., \& Ryan, R. M. (2008). Hedonia, eudaimonia, and well-being: An introduction. Journal of Happiness Studies, 9(1), 1-11.

Delle Fave, A., Brdar, I., Freire, T., Vella-Brodrick, D., \& Wissing, M. P. (2011). The Eudaimonic and hedonic components of happiness: Qualitative and quantitative findings. Social Indicators Research, 100(2), 185-207.

Ford, M. T., Cerasoli, C. P., Higgins, J. A., \& Decesare, A. L. (2011). Relationships between psychological, and behavioral health and work performance: A review and meta-analysis. Work \& Stress, 25(3), 185-204.

Fowers, B. J., Mollica, C. O., \& Procacci, E. N. (2010). Constitutive and instrumental goal orientations and their relations with eudaimonic and hedonic well-being. The Journal of Positive Psychology, 5(2), $139-153$.

Furnham, A. (2008). Personality and intelligence at work: Exploring and explaining individual differences at work. Oxford: Routledge.

Hallberg, U. E., Johansson, G., \& Schaufeli, W. B. (2007). Type a behavior and work situation: Associations with burnout and work engagement. Scandinavian Journal of Psychology, 48(2), 135-142.

Huta, V., \& Waterman, A. S. (2014). Eudaimonia and its distinction from hedonia: Developing a classiffication and terminology for understanding conceptual and operational definition. Journal of Happiness Studies, 15(6), 1425-1456. doi:10.1007/s10902-0139485-0.

Jain, A. K. (2010). Data clustering: 50 years beyond k-means. Pattern Recognition Letters, 31(8), 651-666.

Jayawickreme, E., Forgeard, M. C., \& Seligman, M. P. (2012). The engine of well-being. Review of General Psychology, 16(4), 327-342. doi:10.1037/a0027990.

Keyes, C. L. M. (1998). Social well-being. Social Psychology Quarterly, 61(2), 121-140.

Keyes, C. M., Hysom, S. J., \& Lupo, K. L. (2000). The positive organization: Leadership legitimacy, employee well-being, and the bottom line. The Psychologist-Manager Journal, 4(2), 143-153. doi:10. 1037/h0095888.
Kristof, A. L. (1996). Person-organization fit: An integrative review of its conceptualizations, measurement and implications. Personnel Psychology, 49(1), 1-49.

Kristof-Brown, A. L., \& Billsberry, J. (2012). Organizational fit: Key issues and new directions. John Wiley \& Sons.

Meyer, J. P., \& Allen, N. J. (1991). A tree-component conceptualization on organizational commitment. Human Resource Management Review, 1(1), 61-89.

Miller, J., Woehr, D., \& Hudspeth, N. (2002). The meaning and measurement of work ethic: Construction and initial validation of a multidimensional inventory. Journal of Vocational Behavior, 60, 451-489.

Neuberger, O., \& Allerbeck, M. (1978). Measurement and analysis of satisfaction with work. Bern: Rubber.

Page, K. M., \& Vella-Brodrick, D. A. (2009). The "what", "why" and "how" of employee well-being: A new model. Social Indicators Research, 90(3), 441-458.

Ryff, C. D. (1989). Happiness is everything, or is it? Explorations on the meaning of psychological well-being. Journal of Personality and Social Psychology, 57(6), 1069-1081.

Ryff, C. D., \& Keyes, C. L. M. (1995). The structure of psychological well-being revisited. Journal of Personality and Social Psychology, 69(4), 719-727.

Schaufeli, W. B., \& Bakker, A. B. (2004). Job demands, job resources and their relationship with burnout and engagement: A multi-sample study. Journal of Organizational Behavior, 25, 293-315.

Schermelleh-Engel, K., Moosbrugger, H., \& Müller, H. (2003). Evaluating the fit of structural equation models: Tests of significance and descriptive goodness-of-fit measures. Methods of Psychological Research Online, 8, 23-74.

Schueller, S. M., \& Seligman, M. E. P. (2010). Pursuit of pleasure, engagement, and meaning: Relationships to subjective and objective measures of well-being. The Journal of Positive Psychology, 5(4), 253-263.

Seligman, M. P. (2011). Flourish: A visionary new understanding of happiness and well-being. New York: Free Press.

Sirgy, M. J. (2006). Developing a conceptual framework of employee well-being (EWB) by applying goal concepts and findings from personality-social psychology. Applied Research in Quality of Life, 1,7-38. doi:10.1007/s11482-006-9000-4.

Spector, P. E. (1997). Job satisfaction. Thousand Oaks: SAGE Publications.

Steger, M. F., \& Dik, B. J. (2009). If one is looking for meaning in life, does it help to find meaning in work? Applied Psychology: Health and Well-Being, 1(3), 303-320. doi:10.1111/j.1758-0854.2009. 01018.x.

Steger, M. F., Dik, B. J., \& Duffy, R. D. (2012). Measuring meaningful work: The work and meaning inventory (WAMI). Journal of Career Assessment, 20(3), 322-337.

Steinley, D., \& Brusco, M. J. (2011). Choosing the number of clusters in k-means clustering. Psychological Methods. Advance online publication. doi:10.1037/a0023346.

Van Horn, J. E., Taris, T. W., Schaufeli, W. B., \& Schreurs, P. G. (2004). The structure of occupational well-being: A study among Dutch teachers. Journal of Occupational and Organizational Psychology, 77(3), 365-375. doi:10.1348/0963179041752718.

Wrzesniewski, A., \& Dutton, J. E. (2001). Crafting a job: Revisioning employees as active crafters of their work. Academy of Management Review, 26(2), 179-201.

Wrzesniewski, A. (2003). Finding positive meaning in work. In K. Cameron \& J. Dutton (Eds.), Positive organizational scholarship: Foundations of a new discipline, (296-308). Berrett-Koehler Publishers.

Wrzesniewski, A., Dutton, J. E., \& Debebe, G. (2003). Interpersonal sense making and the meaning of work. Research in Organizational Behavior, 25, 93-135. 